\title{
AÇÃO DE EXTRATOS DE SORGO NA GERMINAÇÃO DE SEMENTES DE MILHO, ALFACE E CORDA-DE-VIOLA (Ipomoea SP.)
}

\author{
TALITA CAMARGOS GOMES ${ }^{1}$, DÉCIO KARAM²${ }^{2}$, CIDÁLIA GABRIELA SANTOS MARINHO', \\ BIANCA ASSIS BARBOSA MARTINS ${ }^{3}$, MARIA LÚCIA FERREIRA SIMEONE² \\ e FABIANO OKUMURA ${ }^{4}$
}

${ }^{1}$ Universidade Federal de São João del-Rei, Sete Lagoas-MG Brasil, talitacamargos21@gmail.com,gabriela@ufsj.edu.br

${ }^{2}$ Embrapa Milho e Sorgo, Sete Lagoas-MG, Brasil,decio.karam@embrapa.br, marialucia.simeone@embrapa.br,

${ }^{3}$ Universidade de São Paulo, Centro de Energia Nuclearna Agricultura,m.babmarti@gmail.com

${ }^{4}$ Embrapa Pecuária Sudeste, São Carlos - SP, Brasil, fabiano.okumura@embrapa.br

Revista Brasileira de Milho e Sorgo, v.17, n.1, p. 168-176, 2018

\begin{abstract}
RESUMO - O controle de plantas daninhas de forma agroecológica se faz necessário uma vez que os herbicidas são hoje uma das maiores causas de contaminação do homem e do ambiente. Este estudo objetivou identificação e quantificação de sorgoleone a partir de três genótipos de sorgo e a avaliação da ação desses extratos na germinação de sementes de milho, corda-de-viola e alface. A obtenção dos extratos utilizados foi a partir de 200 raízes/genótipo. A quantificação dos extratos foi realizada por LC-MS/MS. Foram avaliados a porcentagem de germinação e o índice de velocidade de germinação de sementes de milho, corda-de-viola e alface. Os tratamentos foram dispostos em delineamento inteiramente casualizados, com três repetições por 7 dias no escuro. Não há relação direta entre a produção de massa de extrato e a quantidade de sorgoleone produzido. A produção total de extratos a partir de raízes de plântulas de sorgo e a concentração de sorgololeone no tecido celular são variáveis entre genótipos de sorgo. Extratos com sorgoleone não afetaram a germinação e o índice de velocidade de germinação de sementes de milho. Apenas o índice de velocidade de germinação de sementes de alface foi alterado pelos extratos de sorgo. A germinação e o índice de velocidade de germinação da espécie corda-de-viola são afetados por extratos com sorgoleone.
\end{abstract}

Palavras-chave: efeito alelopático, exsudato radicular, sorgoleone.

\section{SORGHUM EXTRACTS ACTION IN CORN SEED GERMINATION, LETTUCE AND MORNING GLORY (Ipomoea sp.)}

\begin{abstract}
An agroecological weed control is desired once nowadays herbicides are the major causes of contamination of the environment. This work describes the identification and quantification of sorgoleone (SGL) from three sorghum genotypes. The activity of these extracts on the germination of maize, morning glory (Ipomoea sp.) and lettuce seeds was availed. The extracts were obtained from 200 roots/genotype. The quantification was done by LC-MS/MS procedure. The germination percentage $(\% \mathrm{G})$ and germination rate index (IVG) contents of maize, morning glory and lettuce seeds were evaluated, and the treatments were arranged in a completely randomized design, with three replicates for 7 days in the dark. There is no direct relationship between the mass production of extract and the amount of SGL produced. The total yield of extracts from sorghum seedlings roots, and the concentration of SGL in the cell tissue are variable among sorghum genotypes. Extracts with sorgoleone did not affect the germination and IVG of corn seeds. Only the IVG of lettuce seeds was altered by sorghum extracts. The germination and IVG of the morning glory species are affected by extracts with SGL.
\end{abstract}

Keywords: allelopathic effect, root exudates, sorgoleone.

Versão on line ISSN 1980-6477 - http://www.abms.org.br 
A busca por uma agricultura sustentável com produtos mais saudáveis que proporcionem uma saúde melhor implica a redução do uso de pesticidas, que é uma ação de extrema importância e urgência. Entretanto, os problemas fitossanitários estão presentes nas lavouras e precisam ser manejados. Como exemplo, temos a interferência causada pelas plantas invasoras, as quais causam perdas consideráveis na condução das grandes culturas (Silva et al., 2017), promovendo o alto consumo de herbicidas (Sindicato Nacional da Indústria de Produtos para Defesa Vegetal, 2013), que muitas vezes são aplicados da forma incorreta, contaminando o meio ambiente (Queiroz et al., 2011). Por esse motivo, torna-se necessário o desenvolvimento de novas tecnologias para o controle eficaz destas, com o menor impacto possível no ambiente.

Uma alternativa é a utilização de substâncias alelopáticas (Trezzi et al., 2005; Lima et al., 2016; Borella et al., 2017), ou seja, substâncias que causam interferência no desenvolvimento de plantas e que poderiam ser empregadas na agricultura com o objetivo de suprimir o desenvolvimento de plantas invasoras efetuando assim o seu controle. De acordo com Netzly e Butler (1986), o sorgoleone, substância proveniente do metabolismo secundário de plantas de sorgo, já foi observado causando efeito deletério em plantas. Por esse motivo esta substância vem sendo estudada no manejo de plantas daninhas, como uma forma de controle alternativo, com menos agressividade ao meio ambiente (Serafin, 2007), bem como no desenvolvimento de novos modelos de herbicidas naturais (Dayan et al., 2007).

Assim, é de suma importância a realização de estudos que determinem os efeitos do sorgoleone sobre plantas daninhas. Portanto, o objetivo do estudo foi identificar e quantificar o composto sorgoleone presente no exsudato radicular de 3 genótipos de sor- go, de características agronômicas distintas, e realizar uma avaliação prévia destes extratos na germinação de espécies.

Os experimentos foram realizados na Embrapa Milho e Sorgo, em Sete Lagoas-MG, nos laboratórios de Agroquímica e de Manejo de Plantas Daninhas e Dinâmica de Herbicidas da Embrapa Milho e Sorgo. Os reagentes utilizados foram cedidos pelo laboratório de Agroquímica, e as sementes dos genótipos de sorgo utilizados, BRS 716, BR 007 B e CMSXS 206 B, cedidas pelo banco de sementes da Embrapa. Para determinar a quantidade de sorgoleone nos tratos avaliados, foi necessário um padrão analítico conhecido, que foi cedido pelo laboratório de Agroquímica da Embrapa.

O primeiro experimento constou da quantificação de sorgoleone, proveniente de extrato de raízes de 3 genótipos de sorgo (BRS 716, BR 007 B e CMSXS 206 B). Foram separadas 200 sementes de cada genótipo em duplicata, que passaram por procedimento de desinfecção e germinação, segundo metodologia de Franco et al. (2011). Após os sete dias, as raízes foram destacadas e foi obtido seu peso fresco. Cada grupo de 200 raízes foi mergulhado por 5 minutos em solução extratora de ácido acético glacial em diclorometano na concentração de $0,0025 \% \mathrm{v} / \mathrm{v}$, filtrada em algodão, e o solvente concentrado, em evaporador rotatório a $30{ }^{\circ} \mathrm{C}$. Posteriormente, obteve-se a massa seca das raízes após a secagem em estufa a $65^{\circ} \mathrm{C}$ por 72 horas.

Os extratos obtidos foram analisados em um sistema de cromatografia líquida Surveyor, acoplado ao espectrômetro de massas da Thermo Scientifc, modelo TSQ Quantum Access Max quadrupolo de triplo estágio LC-MS/MS. A fase móvel utilizada foi solução de ácido acético $0,1 \%(\mathrm{v} / \mathrm{v})$ e acetonitrila na proporção de 25:75 no modo negativo em um fluxo de $0,4 \mathrm{~mL}$ por minuto. A coluna utilizada foi 
uma C18 da ACE Gold, 2,1 x $150 \mathrm{~mm}$, tamanho de partícula de $3 \mu \mathrm{m}$. A temperatura do forno da coluna foi de $30{ }^{\circ} \mathrm{C}$ e o volume de injeção das amostras foi de $10,0 \mu \mathrm{L}$. Os parâmetros de espectrometria de massas utilizados foram: modo negativo, voltagem de $4 \mathrm{kV}$, temperatura de vaporização de $350{ }^{\circ} \mathrm{C}$, temperatura de capilar de $270{ }^{\circ} \mathrm{C}$, gás de secagem em vazão de 8 litros por minuto. Para a construção da curva analítica foi utilizado um padrão purificado de sorgolone obtido pelo Laboratório de Agroquímica nas concentrações de 150, 300, 450, 600, 750, 900 ppb de sorgoleone em metanol com um $\mathrm{R}^{2}=0,999$. A detecção do teor de sorgoleone nos exsudatos foi realizada pela comparação do tempo de retenção do padrão pelo íon molecular $\mathrm{m} / \mathrm{z}$ 357. As transições utilizadas foram: $357 \rightarrow 123,090$ (234) (quantificação), $357 \rightarrow 137$, 110 (220) e $357 \rightarrow 164,970$ (193) (confirmação). Avaliaram-se a produção total de extratos das 200 radículas dos três genótipos de sorgo pela massa seca de radículas e a produção de sorgoleone. As variáveis testadas foram submetidas à análise de variância pelo teste F e comparadas pelo teste de Tukey ao nível de 5\% de significância pelo programa SISVAR 5.6.

O segundo experimento constou da avaliação dos efeitos dos extratos com sorgoleone, provenientes de radículas dos 3 genótipos de sorgo, sobre a germinação e o crescimento inicial de sementes de milho (Zea mays), que foram obtidas pelo banco de semen- tes da Embrapa Milho e Sorgo; da espécie daninha corda-de-viola (Ipomoea sp.), cujas sementes foram coletadas na área experimental da unidade agropecuária; e alface (Lactuca sativa), como espécie bioindicadora. Os extratos foram diluídos com álcool P.A. 95\%, obtendo-se solução estoque e, a partir desta, houve 5 diluições seriadas que foram utilizadas como tratamentos $(6,25 ; 12,5 ; 25$ e 50 e $100 \%)$ (Tabela 1$)$, e duas testemunhas: apenas água destilada e outra com o solvente álcool. Foi realizado um teste de potencial osmótico (dados não apresentados) em que não houve efeito osmótico nas soluções testadas.

Foram pipetados $3 \mathrm{ml}$ de solução de extrato diluído em álcool em caixas gerbox de $250 \mathrm{ml}$ $(11 \times 11 \times 3,5 \mathrm{~cm})$ de acrílico, forradas com papel-filtro autoclavado, e aguardou-se 12 horas para a completa evaporação do solvente. Foram colocadas 25 sementes de cada espécie. Os experimentos foram desenvolvidos em câmara de germinação, durante 7 dias no escuro e com temperatura média de $27^{\circ} \mathrm{C}$. As sementes foram contadas diariamente e foram consideradas germinadas aquelas com extensão radicular igual ou maior a 2 mm (Juntila, 1976). A partir dos resultados obtidos, calcularam-se as variáveis índice de velocidade de germinação (IVG) e porcentagem de germinação (\%G). O delineamento utilizado foi completamente casualizado com 3 repetições. Os valores de germinabilidade foram transformados por arc sen $\sqrt{ } \mathrm{x} / 100$ e os dados

Tabela 1 - Concentrações dos extratos de raízes de plântulas de sorgo a serem testadas.

\section{Concentrações testadas (ppm)}

\begin{tabular}{cccc}
\hline Proporções (\%) & BRS 716 & BR 007 B & CMSXS 206 B \\
\hline $\mathbf{1 0 0}$ & 138,94 & 79,68 & 49,30 \\
$\mathbf{5 0}$ & 69,47 & 39,84 & 24,65 \\
$\mathbf{2 5}$ & 34,73 & 19,92 & 12,33 \\
$\mathbf{1 2 , 5}$ & 17,37 & 9,96 & 6,16 \\
$\mathbf{6 , 2 5}$ & 8,68 & 4,98 & 3,08 \\
\hline
\end{tabular}


foram submetidos à análise de variância pelo teste $\mathrm{F}$ e as médias, comparadas pelo teste de Tukey, ambos com 5\% de significância pelo programa SISVAR.

No primeiro experimento, não houve diferença significativa entre a produção de massa de extrato produzido pelas 200 radículas dos três genótipos $(\mathrm{F}=$ $0,199 ; \mathrm{P}=0,829)$, mas foi significativa a diferença entre o peso de extrato por massa seca de raiz (Tabela2).

Quanto à quantidade de sorgoleone contida nos extratos, houve diferença significativa entre os três genótipos avaliados com $\mathrm{F}=60,374$ e $\mathrm{P}=0,0037$, sendo o genótipo BRS 716 com maior teor de sorgoleone, seguido de BR 007 B e CMSXS 206 B (Tabela 3). A variação de produção de sorgoleone entre os genótipos foi cerca de 64,5\% entre o menor produtor (CMSXS 206 B) e $42,6 \%$ entre o mediano (BR 007 B). Este resultado corrobora com os trabalhos de Nimbal et al. (1996), Ferreira et al. (1999), Trezzi et al. (2005), Uddin et al. (2009), Franco et al. (2011) e May et al. (2016), que também constataram que existe variação entre a quantidade de produção de sorgoleone nas raízes em diferentes genótipos de sorgo. A diferença encontrada na quantidade de sorgoleone produzida em função de cultivares de sorgo deve-se provavelmente às características genéticas de cada cultivar, além das condições de ambiente, em particular à quantidade de água disponível para os pelos radiculares, idade vegetal, meio ambiente (Hess et al., 1992; Alsaadawi et al., 2015). Também foi significativa a quantidade de sorgoleone pela massa seca de raízes, ou seja, a concentração de sorgoleone no tecido radicular, com $\mathrm{F}=70,589$ e $\mathrm{P}=$ 0,003 com uma diferença de $62 \%$ entre a maior e menor concentração $\left(10,89\right.$ a 28,61 mg g $\left.{ }^{-1} \mathrm{SGL} \mathrm{MSR}^{-1}\right)$ (Tabela 2). Trabalhos como o de Nimbal et al. (1996), que avaliaram 25 genótipos de sorgo, e Trezzi et al. (2005), que avaliou 41 genótipos de sorgo, observaram valores de produção entre 0,4 e 10,7 mg100 radículas $^{-1}$.

De acordo com a literatura, o composto sorgoleone é predominante em extratos hidrofóbicos de raízes de plântulas de sorgo. Assim, neste trabalho, dos três genótipos testados, chegou-se à conclusão de que 74,43\% (BRS 716), 82, 17\% (CMSXS 206 B) e $38,56 \%$ (BR 007 B) da constituição da massa seca do extrato é sorgoleone. Apenas o genótipo BR 007 B apresentou um resultado diferente quando comparado aos teores de sorgoleone encontrados pelos trabalhos de Nimbal et al. (1996); Trezzi et al. (2005); Franco (2011), que concluíram que cerca de 73 a 99\% da massa constituinte de um extrato de raízes de plântulas de sorgo é sorgoleone. Ferreira et al. (1999) encontraram para o genótipo BR 007B 93\% de sorgoleone no extrato, porém com menor produção (11,4 mg de SGL $\mathrm{g} \mathrm{MSR}^{-1}$ ). Portanto, o resultado para esse genótipo deverá ser repetido para a verificação do resultado,

Tabela 2 - Genótipos de sorgo utilizados, características agronômicas, produção de extratos em 200 raízes, determinadas a parir de sementes germinadas em caixas gerbox, em câmara de crescimento. Embrapa Milho e Sorgo, Sete Lagoas-MG, 2017.

\begin{tabular}{lccc}
\hline Genótipo & Características & $\begin{array}{c}\text { Massa seca 200 raízes } \\
(\text { MSR })(\mathbf{g})\end{array}$ & $\begin{array}{c}\text { Produção total de extratos } \\
\left(\mathbf{m g ~ 2 0 0} \text { radículas }^{-1}\right)\end{array}$ \\
\hline BRS 716 & Biomassa & $0,366 \pm 0,06$ & $14,0 \mathrm{~A}$ \\
BR 007 B & Sacarino & $0,356 \pm 0,06$ & $15,5 \mathrm{~B}$ \\
CMSXS 206 B & Forrageiro & $0,341 \pm 0,05$ & $4,5 \mathrm{C}$ \\
\hline
\end{tabular}


Tabela 3 - Genótipos de sorgo utilizados, massa de sorgoleone (SGL) encontrada em cada genótipo, concentração de SGL por massa seca de 200 radículas. Embrapa Milho e Sorgo, Sete Lagoas-MG, 2017.

\begin{tabular}{lcc}
\hline Genótipo & Sorgoleone $\mathbf{( m g )}$ & $\mathbf{~ m g ~ g ~}^{\mathbf{1}} \mathbf{( S G L ~ \mathbf { M S R } ^ { - \mathbf { 1 } } )}$ \\
\hline BRS 716 & $10,42 \mathrm{~A}$ & $28,61 \mathrm{~A}$ \\
BR 007 B & $5,98 \mathrm{~B}$ & $16,71 \mathrm{~B}$ \\
CMSXS 206 B & $3,70 \mathrm{C}$ & $10,89 \mathrm{C}$ \\
\hline
\end{tabular}

$\mathrm{SGL}=$ Sorgoleone

MS $=$ Massa seca a $65^{\circ} \mathrm{C}$

Letras iguais, na coluna, não diferem entre si pelo teste de Tukey a 5\% de significância.

uma vez que a concentração de sorgoleone poderá ser influenciada pela quantidade de água disponível (Uddin et al., 2010). Para o genótipo BRS716, o resultado encontrado foi aproximadamente o triplo do teor encontrado para o genótipo CMSXS 206B e muito próximo ao valor encontrado por May et al. (2016), que foi 32,76 mg de SGL/g MSR ${ }^{-1}$ ). É interessante observar que os genótipos de sorgo variam não somente na quantidade de sorgoleone produzida, mas também em sua pureza. Estes resultados contribuem para o esclarecimento dos dados obtidos por Alsaadawi et al. (2015), que encontraram consideráveis diferenças alelopáticas entre exsudatos de diferentes genótipos de sorgo. Assim, o conhecimento da variabilidade da produção de extrato e da concentração de sorgoleone contida nele possibilita a escolha da melhor cultivar para futuros testes em laboratório e em campo.

No segundo experimento, não houve diferença significativa entre as testemunhas (água e etanol) para nenhuma das três espécies testadas, mostrando que não há interferência do álcool para os parâmetros avaliados.

Também não foram significativos os testes $\mathrm{F}$ para os parâmetros germinação $(\% \mathrm{G})(\mathrm{F}=0,54 ; \mathrm{P}=$ 0,902) e Índice de Velocidade de Germinação (IVG) $(\mathrm{F}=1,53 ; \mathrm{P}=0,144)$ das sementes de milho tanto entre suas testemunhas quanto entre os 3 genótipos e as 5 concentrações (Figura 1). Mas observa-se uma leve inibição de germinação nas 5 concentrações do genótipo CMSXS 206 B em relação aos outros dois genótipos (BRS 716 e BR 007 B) (Figura 1).

Quanto às sementes da espécie corda-de-viola, houve diferença significativa do genótipo CMSXS 206 B para as testemunhas e os outros dois genótipos de sorgo (BRS 716 e BR $007 \mathrm{~B}$ ), para as variáveis $\% \mathrm{G}(\mathrm{F}=14,12 ; \mathrm{P}<0,0001)$ e IVG $(\mathrm{F}=14,37$; $\mathrm{P}<$ $0,0001)$ (Figuras 2 e 3). Em relação à média das testemunhas, o IVG variou a mais em 66; 66; 68 e 65\% nas proporções de 6,$25 ; 12,5 ; 25$ e $50 \%$, respectivamente. A análise destes dados remete que CMSXS 206 B atrasa a germinação de sementes de corda-deviola em comparação aos outros genótipos de sorgo, entretanto, há um aumento do número de sementes germinadas (Figuras 2 e 3).

Não houve diferença na porcentagem de germinação de sementes de alface $(\mathrm{F}=1,35 ; \mathrm{P}=0,2237)$ em relação às testemunhas e a concentrações e genótipos. Estes dados se assemelham aos resultados encontrados por Trezzi et al. (2005), quem também testou a ação alelopática de extrato de sorgo contendo sorgoleone em sementes de alface. Já para a variável IVG houve diferença entre as concentrações de 6,25; 12,$5 ; 25,50$ e $100 \%$ do genótipo CMSXS $206 \mathrm{~B}(\mathrm{~F}=$ $4,54 ; \mathrm{P}=0,0001)$ para as testemunhas e as concentrações dos outros dois extratos de raízes de sorgo (BRS 716 e BR 007 B) (Figura 4). O tratamento 17 (100\% CMSXS 206 B) teve maior valor de IVG (Figura 4). 


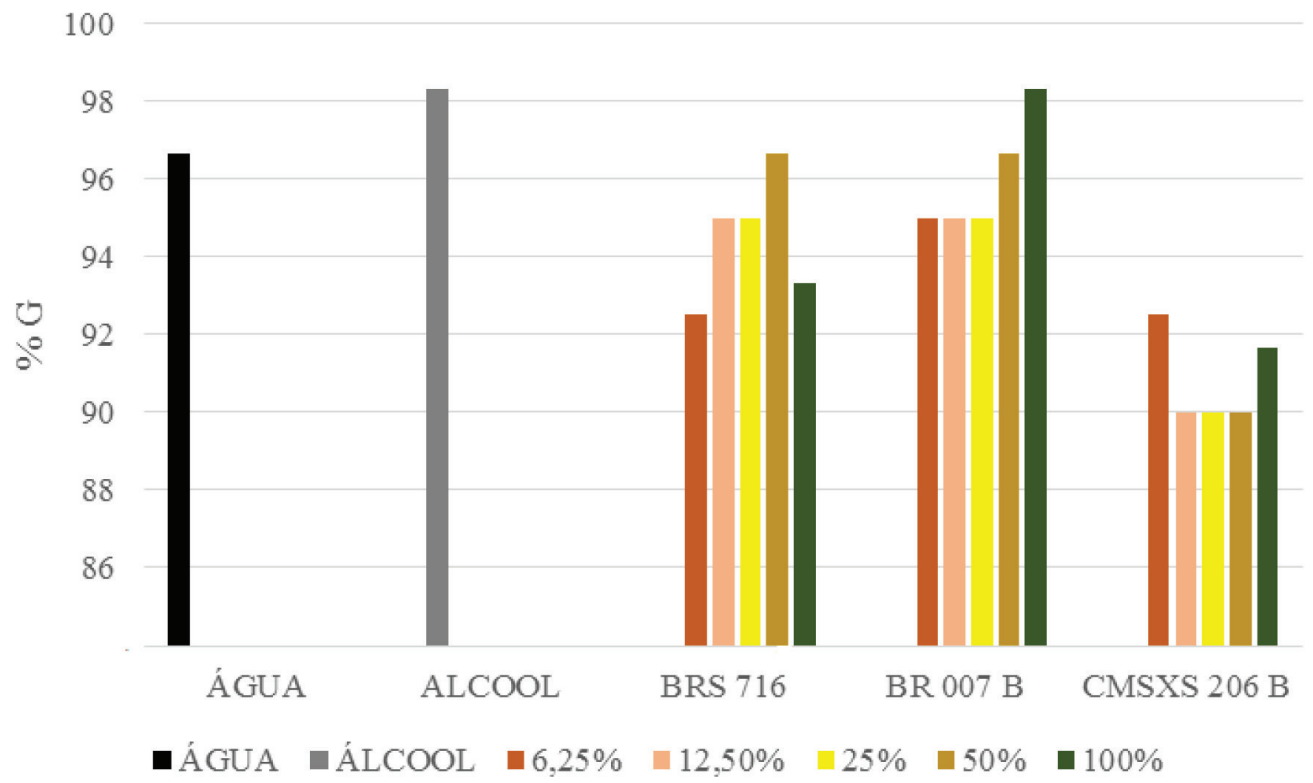

Figura 1-Porcentagem de sementes de milho germinadas sob o efeito de extratos de raízes de plântulas de sorgo dos genótipos BRS 716, BR 007 B, CMSXS 206 B em 5 concentrações durante 7 dias no escuro. Os dados foram retransformados para porcentagem. Embrapa Milho e Sorgo, Sete Lagoas-MG, 2017.

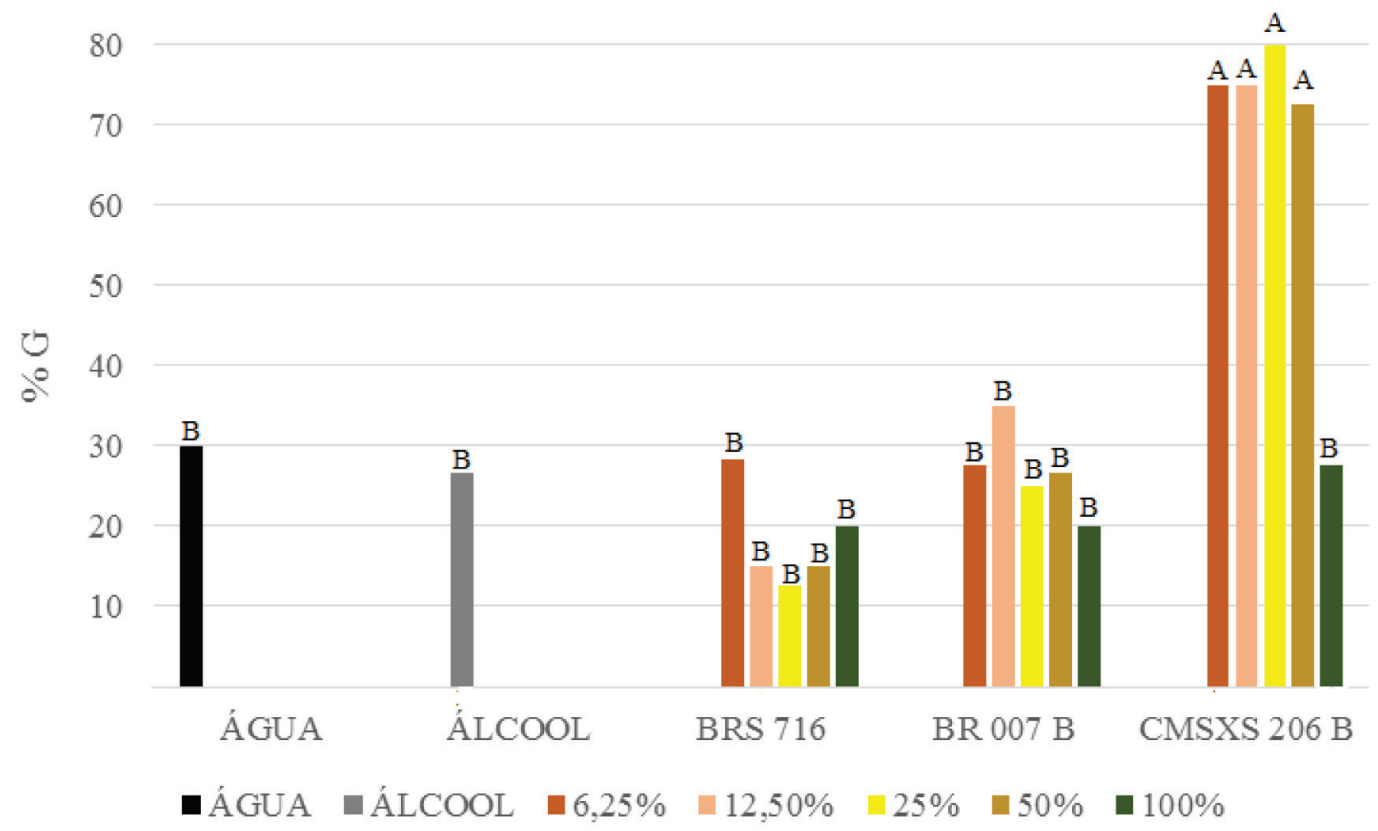

Figura 2-Porcentagem de sementes germinadas das espécies de corda-de-viola e suas respectivas testemunhas, sobre o efeito de extratos de raízes de plântulas de sorgo dos genótipos BRS 716, BR 007 B, CMSXS 206 B em 5 concentrações durante 7 dias no escuro. Os dados foram retransformados para porcentagem. Embrapa Milho e Sorgo, Sete Lagoas-MG, 2017. Letras iguais, na coluna, não diferem entre si pelo teste de Tukey a 5\% de significância. 


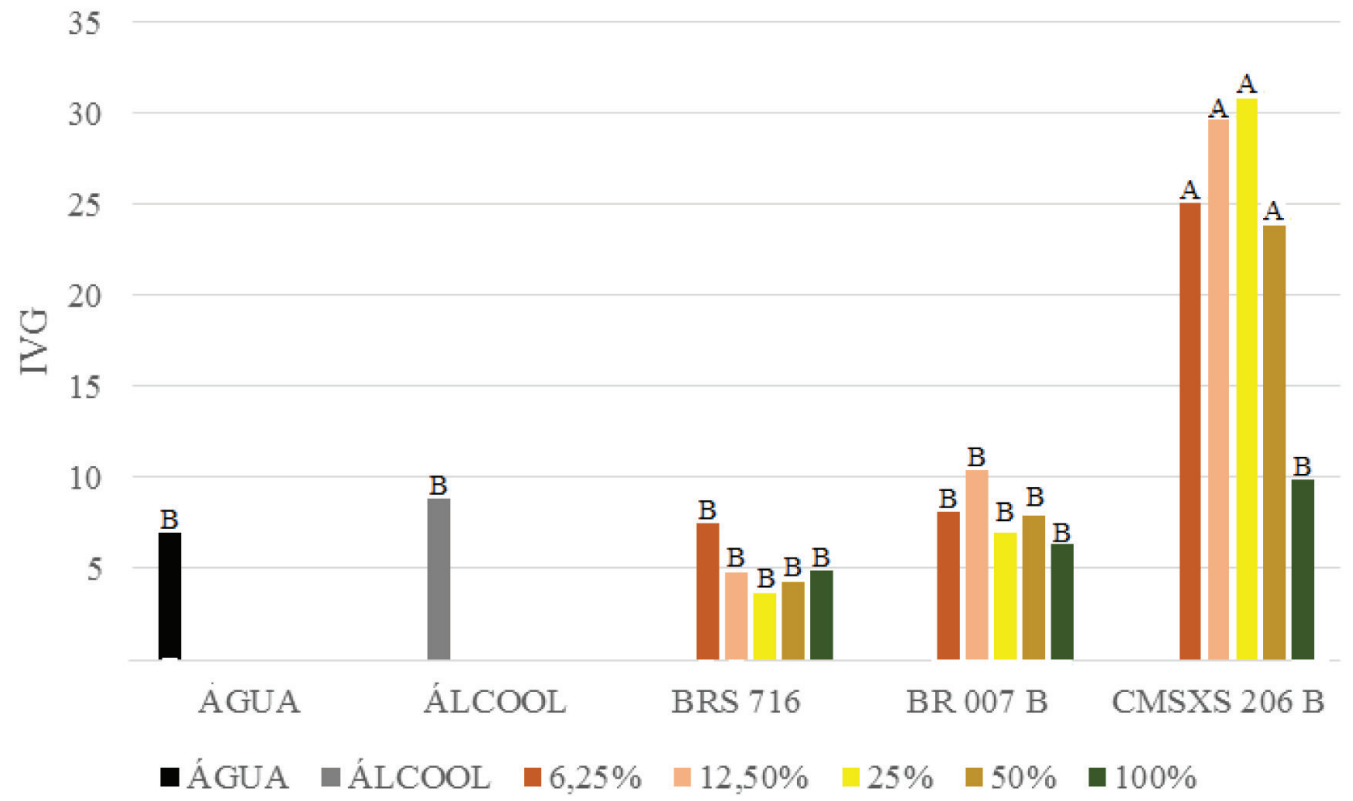

Figura 3-Índice de velocidade de germinação de sementes de corda-de-viola e suas respecivas testemunhas, sobre o efeito de extratos de raízes de plântulas de sorgo dos genótipos BRS 716, BR 007 B, CMSXS 206 B em 5 concentrações durante 7 dias no escuro. Embrapa Milho e Sorgo, Sete Lagoas-MG, 2017. Letras iguais, na coluna, não diferem entre si pelo teste de Tukey a 5\% de significância.

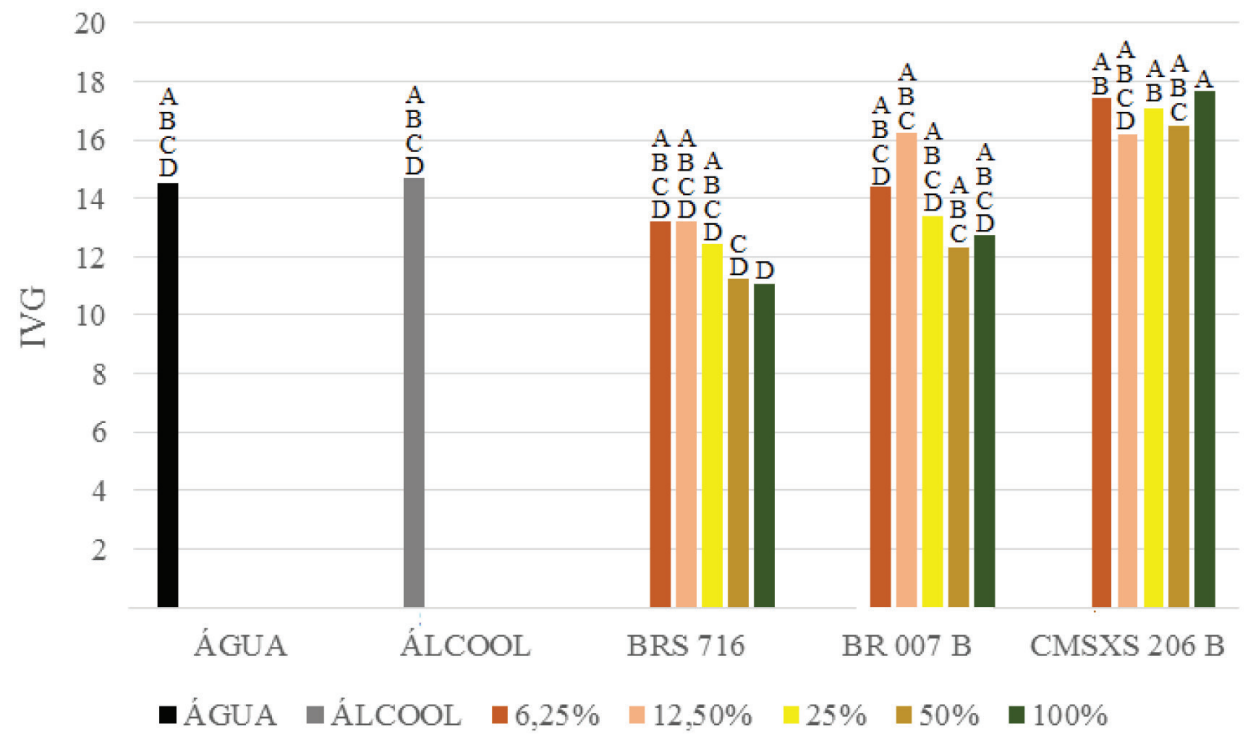

Figura 4-Índice de velocidade de germinação de sementes de alface e suas respecivas testemunhas, sobre o efeito de extratos de raízes de plântulas de sorgo dos genótipos BRS 716, BR 007 B, CMSXS 206 B em 5 concentrações durante 7 dias no escuro. Embrapa Milho e Sorgo, Sete Lagoas-MG, 2017. Letras iguais, na coluna, não diferem entre si pelo teste de Tukey a 5\% de significância. 
Os extratos produzidos por raízes de sorgo podem ter efeito residual quando os valores de IVG são maiores. Segundo Ferreira \& Áquila (2000), a germinação é menos sensível às substâncias aleloquímicas do que o crescimento e desenvolvimento da plântula. Nesse sentido, sementes com valores de IVG maiores, demoram mais tempo para germinar, apresentando menores tamanhos e anormalidades que podem resultar de efeitos reduzidos e podem ficar mais suscetíveis a estresses, tendo menor chance de competir por recursos.

\section{Conclusões}

Não há relação direta entre a produção de massa de extrato e a quantidade de sorgoleone produzida. A produção total de extratos a partir de raízes de plântulas de sorgo e a concentração de sorgoleone no tecido celular são variáveis entre genótipos de sorgo.

Extratos com sorgoleone não afetaram a germinação e o IVG de sementes de milho. Apenas o IVG de sementes de alface foi alterado pelos extratos de sorgo. A germinação e o IVG da espécie corda-deviola são afetados por extratos com sorgoleone.

\section{Agradecimentos}

À Fundação de Amparo à Pesquisa de Minas Gerais pela concessão de bolsa de produtividade à primeira autora.

\section{Referências}

ALSAADAWI, I. S.; AL-KHATEEB, T. A.; HADWAN, H. A.; LAHMOOD, N. R. A chemical basis for differential allelopathic potential of root exudates of Sorghum bicolor L. (Moench) cultivars on companion weeds. Journal Allelopathy Interactions, v. 1, n. 1, p. 49-55, 2015.
BORELLA, J.; LESCHEWITZ, R.; TRAUTENMULLER, J. W.; SILVA, D. R. O.; SCHMIDT, D. Efeito alelopático de extrato de canola (Brassica napus) sobre a fase de germinação da cultura da soja. Brazilian Journal of Biosystems Engineering, Tupã, v. 11, n. 1, p. 18-25, 2017. DOI: 10.18011/bioeng2017v11n1p18-25.

DAYAN, F. E.; WATSON, S. B.; NANAYAKKARA, N. P. D. Biosynthesis of lipid resorcinols and benzoquinones in isolated secretory plant root hairs. Journal of Experimental Botany, Oxford, n. 58, n. 12, p. 3263-3272, 2007. DOI: $10.1093 / \mathrm{jxb} / \mathrm{erm} 173$.

FERREIRA, A. G. ÁQUILA, M. E. A. Alelopatia: uma área emergente da ecofisiologia. Revista Brasileira de Fisiologia Vegetal. Londrina, v. 12, p. 175-205, 2000.

FERREIRA, M. L.; BARBOSA, L. C. A.; DEMUNER, A. J.; SILVA, A. A.; WAKIL, J. Análise e quantificação da sorgoleona em diferentes cultivares de sorgo (Sorghum bicolor L.). Acta Scientiarum, Maringá, v. 21, n. 3, p. 565-570, 1999.

FRANCO, F. H. S.; MACHADO, Y.; TAKAHASHI, J. A.; KARAM, D.; GARCIA, Q. S. Quantificação de sorgoleona em extratos e raízes de sorgo sob diferentes períodos de armazenamento. Planta Daninha, Viçosa, MG, v. 29, p. 953-962, 2011. DOI: 10.1590/S0100-83582011000500001.

HESS, D. E.; EJETA, G.; BUTLER, L. G. Selecting sorghum genotypes expressing a quantitative biosynthetic trait that 20 confers resistance to Striga. Phytochemistry, Oxford, v. 31, n. 2, p. 493-497, 1992.

JUNTILA, O. Speed and embryo germination in S. vulgaris and $S$. reflexa as affected by temperature during seed development. Physiology Plant, v. 29, p. 264-268, 1976.

LIMA, C. T.; SIMONETTI, A. P. M. M.; MONTIEL, C. B. Extrato de frutos de crambe sobre a germinação e desenvolvimento inicial de plântulas de trigo e azevém. Acta Tecnológica, São Luís, v. 11, n. 1, p. 57-65, 2016.

MAY, A.; CERDEIRA, A. L.; QUEIROZ, S. C. do N. de; SANTOS, M. de S. dos; CORNIANI, N.; SILVA, E. 
H. F. M. da. Avaliação do teor de sorgoleone presente em extratos de raízes de cultivares de sorgo por cromatografia líquida de alta eficiência (HPLC). Sete Lagoas: Embrapa Milho e Sorgo, 2016. 21 p. (Embrapa Milho e Sorgo. Boletim de Pesquisa e Desenvolvimento, 145).

NETZLY, D. H.; BUTLER, L. G. Roots of sorghum exude hydrophobic droplets containing biologically active components. Crop Science, Madison, v. 26, n. 4, p. 775778, 1986.

DOI: 10.2135/cropsci1986.0011183X002600040031x.

NIMBAL, C. I.; PEDERSON, J.; YERKES, C. N.; WESTON, L.; WELLER, S. C. Phytotoxicity and distribution of sorgoleone in grain sorghum germplasm. Journal of Agricultural and Food Chemistry, Easton, v. 44, n. 5, p. 1343-1347, 1996. DOI: 10.1021/jf950561n.

QUEIROZ, G. M. P.; SILVA, M. R.; BIANCO, R. J. F.; PINHEIRO, A.; KAUFMANN, V. Transporte de glifosato pelo escoamento superficial e por lixiviação em um solo agrícola. Quimica Nova, São Paulo, v. 34, n. 2, p. 190195, 2011. DOI: 10.1590/S0100-40422011000200004.

SERAFIN, C. F. Ação do sorgoleone na germinação de sementes de soja e trigo e espécies invasoras. 2007. 62 f. Dissertação (Mestrado em Engenharia Agrícola) Universidade Estadual do Oeste do Paraná, Cascavel, 2007.
SILVA, A. F.; KARAM, D.; GAZZIERO, D. L. P.; ADEGAS, F. S.; VARGAS, L.; SILVA, W. T. Monitoramento de resistência de plantas daninhas a herbicidas no estado de Mato Grosso - safra 2016/2017. Sete Lagoas: Embrapa Milho e Sorgo, 2017. 5 p. (Embrapa Milho e Sorgo. Circular Técnica, 228).

SINDICATO NACIONAL DA INDÚSTRIA, DE PRODUTOS PARA DEFESA VEGETAL. Sindiveg registra crescimento no setor de defensivos em 2013. Moema, 2013. Disponível em: <http://sindiveg.org. br/noticiaonline.php?cod=2338>. Acesso em: 28 ago. 2017.

TREZZI, M. R.; VIDAL, R. A.; KRUSE, N. D. Fitotoxicidade de extratos hidrofóbicos e hidrofílicos de sorgo e milheto. Revista de Ciências Agroveterinárias, Lages, v. 4, n. 1, p. 25-34, 2005.

UDDIN, M. R.; KIM, Y. K.; PARK, S. U.; PYON, J. Y. Herbicidal activity of sorgoleone from grain sorghum root exudates and its contents among sorghum cultivars. Korean Journal Weed Science, v. 29, p. 229-236, 2009.

UDDIN, M. R.; PARK, K. W.; KIM, Y. K.; PARK, S. U.; PYON, J. Y. Enhancing sorgoleone levels in grain sorghum root exudates. Journal of Chemical Ecology, New York, v. 36, n. 8, p. 914-922, 2010.

DOI: $10.1007 / \mathrm{s} 10886-010-9829-8$. 